\title{
ARCHITECTURE AND PHYSIOLOGY OF INSECT CEREBRAL NEUROSECRETORY CELLS ${ }^{1}$
}

\author{
GRANT M. CARROW, ${ }^{2}$ RONALD L. CALABRESE, AND CARROLL M. WILLIAMS \\ The Biological Laboratories, Harvard University, Cambridge, Massachusetts 02138
}

Received July 6, 1983; Revised October 10, 1983; Accepted November 15, 1983

\begin{abstract}
The architecture of neurosecretory cells (NSCs) from each of two bilaterally symmetrical clusters of somata in the brain of the moth, Manduca sexta, was determined by intracellular injection of Lucifer Yellow and horseradish peroxidase. Furthermore, the ionic basis of the action potential in these cells was examined. NSC somata were visualized in the desheathed pupal protocerebrum by their reflective opalescence under direct fiberoptic illumination.

Intracellular staining revealed at least six morphological classes of monopolar neurons distinguishable by the size and position of their somata as well as the patterns of their dendritic fields, axonal pathways, and terminal projections. The number of morphological classes of NSCs is in accord with the estimated number of brain neurohormones-a finding that suggests a different neuroendocrine function for each class. The observed overlap of dendritic fields is consistent with synaptic interaction among NSCs or the sharing of common inputs. Finally, the demonstration of terminal ramifications and varicosities in the corpora cardiaca and corpora allata confirms that these are the neurohemal organs for cerebral NSCs.

Intracellular recordings revealed that the NSC somata had resting membrane potentials of 35 to $45 \mathrm{mV}$ and were electrically excitable; they showed broad (10 to $20 \mathrm{msec}$ ) overshooting action potentials, long hyperpolarizing afterpotentials, and postsynaptic potentials. Impulse amplitude was maintained in the absence of external sodium or in the presence of $10^{-5} \mathrm{M}$ tetrodotoxin, but impulses were completcly and reversibly blocked by $10 \mathrm{~mm}$ cobalt. Postsynaptic potentials were blocked by all three conditions. These results indicate that impulses in the somata are generated primarily by calcium inward currents. Cations, tetrodotoxin, and horseradish peroxidase in the bathing medium did not readily exchange with the extracellular space of the desheathed brain. However, light protease treatment of the brain facilitated ion exchange. These findings provide evidence for the persistence of a blood-brain barrier even in desheathed ganglia.
\end{abstract}

Neuroendocrine systems in insects have been described anatomically on the basis of several complementary investigative approaches. Neurosecretory cell (NSC) somata and neurohemal organs have been located throughout insect central and peripheral nervous systems by the physiological, histochemical, and ultrastructural detection of neurosecretory material (reviewed by Rowell, 1976; Raabe, 1982). The dendritic fields of cerebral neuroendocrine systems have been revealed with silver intensification of retrograde cobalt fills (Pipa, 1978; Koontz and Edwards, 1980; Buys and Gibbs, 1981). However, the complete structure of individual NSCs

\footnotetext{
${ }^{1}$ This work was supported by grants from the National Science Foundation (PCM 8215638 and BNS 8121551) and the National Institutes of Health.

${ }^{2}$ To whom correspondence should be addressed.
}

cannot be elucidated by these methods. Only recently have identification and characterization of individual NSCs been initiated by means of intracellular marking (Carrow et al., 1982; Taghert and Truman, 1982; Zaretsky and Loher, 1982; Carrow, 1983).

Examination of the ionic requirements for NSC electrical activity has revealed that, unlike the situation in most mature nonendocrine neurons, the inward currents appear to be carried in part by calcium. Thus, calcium components were found in action potentials of NSC somata in molluscs (Geduldig and Junge, 1968; Standen, 1975), crayfish (Iwasaki and Satow, 1971), and insects (Orchard, 1976; Miyazaki, 1980). In insects, the sodium component was apparently minimal or absent. Calcium was also reported to play a role in the generation of action potentials in NSC axons of insects (Orchard and Osborne, 1977; Miyazaki, 1980). 
The insect brain is the site of production of at least seven different neurohormones (Rowell, 1976), the most notable of which is prothoracicotropin (PTTH) - a neuropeptide regulator of growth and postembryonic development. The primary PTTH cell somata and neurohemal organs have been identified in the moth, Manduca sexta (Gibbs and Riddiford, 1977; Agui et al., 1979, 1980; Carrow et al., 1981). Moreover, the cell bodies, axon tracts, and dendritic fields of the cerebral NSCs of Manduca have been described in general terms (Nijhout, 1975; Buys and Gibbs, 1981). Thus, the brain of this species provides an exceptionally favorable subject for the morphological and physiological analysis of single NSCs with identified neuroendocrine function.

Structural and physiological characterization of individual cerebral NSCs is a prerequisite for clarifying their functions at the cellular level. We here describe the architecture of individual cerebral NSCs in pupae of $M$. sexta as revealed by the intracellular injection of Lucifer Yellow and horseradish peroxidase. We also describe the ionic basis of the action potentials in these neurons. A preliminary report of part of this work has been presented (Carrow et al., 1982).

\section{Materials and Methods}

Animals. Tobacco hornworms were rearcd at $25^{\circ} \mathrm{C}$ on an artificial diet under a 17-hr light/7-hr dark diapausepreventing photoperiod (Bell and Joachim, 1976). Tissues were dissected from pupae during the first 2 days after pupal eclosion, which is just prior to the initiation of adult development.

Tissue preparation. Brain-retrocerebral complexes (brain with attached corpora cardiaca (CC) and corpora allata (CA)) were removed from unanesthetized pupae along with attached tracheae and gut tissue. The isolated tissues were immersed in a buffered medium, the composition of which is shown in Table I. Brains were immobilized by pinning the immersed gut tissue and tracheae to Sylgard (Dow Corning), and they were then desheathed. A horizontal cut was made with microscissors through the enveloping connective tissue along the anterior aspect, and then an elliptical "cap" of sheath was cut away from the dorsal aspect of the ganglion.

Intracellular recording. Individual NSC somata are observable in the living brain under a dissecting microscope due to their reflective opalescence. Use of direct fiberoptic illumination enhanced visibility, particularly of the cell bodies in the pars lateralis which are otherwise difficult to see. Thus, microelectrodes could be inserted under visual control into any of the cerebral NSCs. The

TABLE I

Compositions of buffered media

\begin{tabular}{lcccccc}
\multicolumn{1}{c}{ Medium $^{a}$} & $\mathrm{NaCl}^{\circ}$ & $\mathrm{CaCl}_{2}$ & $\mathrm{CoCl}_{2}$ & 'I'ris & 'I'ris-HCl & Sucrose \\
\hline Normal & 140 & 5 & & & & 10 \\
$\mathrm{Na}^{+}$-free & & 5 & & 6 & 134 & 10 \\
$\mathrm{Ca}^{9+}$-free & 147 & & & & & 10 \\
$10 \mathrm{mM} \mathrm{Co}{ }^{2+}$ & 120 & 5 & 10 & & & 20 \\
\hline
\end{tabular}

${ }^{a}$ All media contained $5 \mathrm{mM}$ PIPES (piperazinediethanesulfonic acid), $7 \mathrm{mM} \mathrm{KOH,} 1 \mathrm{mM} \mathrm{MgCl}$, $5 \mathrm{mM}$ trehalose, and $5 \mathrm{mM}$ glucose.

${ }^{b}$ In millimolar concentrations. microelectrodes (impedance 40 to 60 megohms) were made from aluminasilicate glass microcapillaries (Haer, $1.0 \mathrm{~mm}$ outer diameter) using an Industrial Associates micropipette puller (model M1); they were filled with 0.5 $\mathrm{M} \mathrm{K}_{2} \mathrm{SO}_{4}$. Current was injected through the same electrode using a bridge circuit (WPI). Permanent records were made using an eight-channel FM tape recorder (A. R. Vetter Co., model A). All experiments were performed at room temperature.

Intracellular dye injection. Each soma was penetrated with a glass micropipette (Haer, as described, or Radnoti Microstar, $1.2 \mathrm{~mm}$ outer diameter, beveled, see Miller, 1979) filled with dye and electrolyte. The tip of the electrode was filled with either a $5 \%$ aqueous solution of Lucifer Yellow (gift from W. Stewart or purchased from Sigma) or a mixture of $5 \%$ horseradish peroxidase (HRP, Worthington or Sigma type VI) and $0.2 \%$ fast green in $0.1 \mathrm{M} \mathrm{K}_{2} \mathrm{SO}_{4}$. The electrodes were then backfilled with electrolytes: $2 \mathrm{M} \mathrm{LiCl}$ for Lucifer Yellow-containing electrodes and $0.1 \mathrm{M} \mathrm{K}_{2} \mathrm{SO}_{4}$ for HRP electrodes. Electrode impedances were 30 to 70 megohms. Both materials were injected using pressure (2 to $15 \mathrm{psi}$ ); alternatively, Lucifer Yellow was iontophoretically injected using hyperpolarizing current (2 to $10 \mathrm{nA}$ for 5 to $10 \mathrm{~min}$ ) (Muller and McMahan, 1976; Stewart, 1978).

Treatment of tissues. Brains containing cells stained with Lucifer Yellow were incubated at $10^{\circ} \mathrm{C}$ for 1 to $4 \mathrm{hr}$. Each brain-retrocerebral complex was then freed of extraneous tissue and transferred to a glass slide. After the withdrawal of all fluid, the tissue was cleared with anhydrous glycerol and gently compressed under the weight of a coverslip. The preparations were either stored at $-18^{\circ} \mathrm{C}$ or viewed and photographed immediatcly using a fluorescence photomicroscope (Zeiss or Leitz).

Brains containing cells injected with horseradish peroxidase were incubated in the buffered medium for 1 day at $10^{\circ} \mathrm{C}$. The tissues were fixed for $6 \mathrm{hr}$ in a mixture of $1 \%$ glutaraldehyde and $1 \%$ paraformaldehyde in $150 \mathrm{~mm}$ buffered sodium cacodylate, $5 \mathrm{mM} \mathrm{CaCl}, \mathrm{pH}$ 7.4. After washing in the buffer overnight, the tissues were incubated for $40 \mathrm{~min}$ at room temperature in $2 \mathrm{ml}$ of a solution of $0.2 \% 3,3^{\prime}$-diaminobenzidine and $0.5 \%$ Trition X-100 in the same buffer. The enzymatic reaction was initiated upon the addition of a few drops of $0.6 \% \mathrm{H}_{2} \mathrm{O}_{2}$ and terminated after $10 \mathrm{~min}$ by replacement of the buffer with $30 \%$ ethanol. The tissues were then dehydrated in a graded series of ethanol, cleared with methyl salicylate, mounted in Permount, and photographed or traced with a camera lucida.

Media for ion exchange. The compositions of media used in ion exchange experiments are given in Table I. Total electrolyte concentration, osmolarity, and $\mathrm{pH}$ were the same for all media. Thus, Tris was substituted for sodium in sodium-free medium, sodium was reduced in cobalt-containing media, and sodium was increased in calcium-free medium; osmolarity was maintained by adjusting sucrose concentration. All media were autoclaved and kept sterile until use, at which time they were oxygenated. Tetrodotoxin (TTX, gift from Y. Kishi) in a citrate buffer ( $\mathrm{pH} \mathrm{6.0)}$ and EGTA were added to the bathing medium immediately before use. 
A

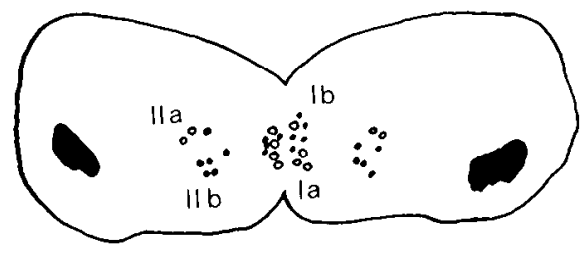

B

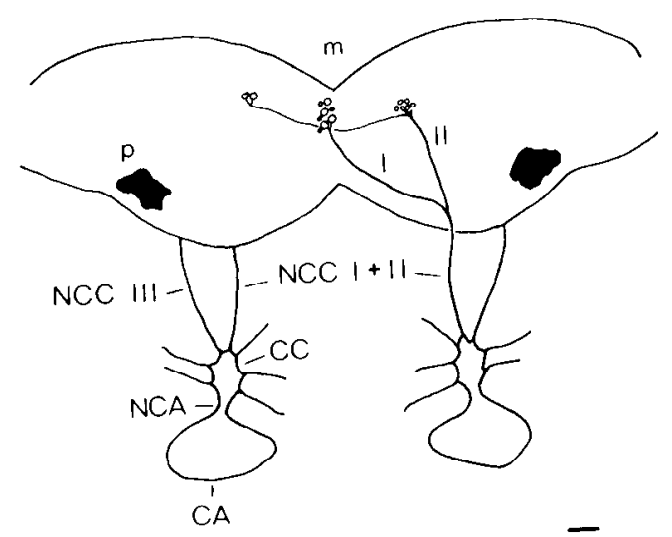

Figure 1. The brain-retrocerebral complex of Manduca sexta. $A$, Camera lucida drawing of NSCs visible in the living pupal brain, dorsal view; anterior is upward. Four groups are labeled: two (Ia, open and $\mathrm{Ib}$, solid) in the pars intercerebralis near the midline of the brain and two (IIa, open and IIb, solid) in the pars lateralis. $B$, Diagram of the brain-retrocerebral complex showing location of cell bodies and axon tracts. Only those cells whose axons exit from the right hemisphere are shown; their contralateral homologues are omitted for clarity. $C A$, corpus allatum; $C C$, corpus cardiacum; $m$, midline of brain; $N C A$, nervus corporis allati; $N C C$, nervus corporis cardiaci; $p$, pigment granules in optic lobe; $I$, axon tract I; $I I$, axon tract II. Bar $=$ $100 \mu$.

\section{Results}

Cell classification. Four bilaterally symmetrical groups of cerebral NSC somata, distinguishable according to size and position, are visible in the living pupal brain and accessible to microelectrode impalement. These four groups, two in the pars intercerebralis and two in the pars lateralis in the dorsal aspect of each hemisphere, are depicted in Figure 1, and their characteristics are listed in Table II. The designations are based upon the conventional numbering of the axon tracts leading to the two pairs of nervi corporis cardiaci (NCC) (Strausfeld, 1976); the numeration differs from that previously applied to this species (Nijhout, 1975; Buys and Gibbs, 1981). A group of small cells in the pars lateralis and a further group in the tritocerebrum are filled by retrograde diffusion of cobalt into the NCC but do not stain with paraldehyde fuchsin (Nijhout, 1975; Borg and Bell, 1977). Because their status as NSCs is equivocal, they were not further considered in the present study.

Intracellular recording. Access to these neurons for microelectrode impalement was facilitated by removal of the sheath that envelops the brain, the use of stiff electrode glass, and the use of direct fiberoptic illumination. Stable penetrations of cell bodies were typically maintained for $10 \mathrm{~min}$ or longer. Indeed, individual somata could be reimpaled several times without apparent changes in their electrical properties. After several hours of manipulation, irreversible damage to a cell was usually indicated by gradual prolongation of impulse duration followed by a decline in resting potential; damaged cells also turned pale yellow and lost much of their opalescence.

Intracellular recordings from more than 75 of each of the four cell types revealed electrically excitable somata with stable resting membrane potentials of 35 to $45 \mathrm{mV}$. As shown in Figure 2, spontaneous action potentials were often observed which sometimes had fairly constant impulse frequency; at other times activity was irregular or the cells were silent. Figure 3 demonstrates that the

TABLE II

Characteristics of the NSCs visible in the living pupal brain of $M$. sexta

\begin{tabular}{rlccr}
\hline Group & Location of Somata & $\begin{array}{c}\text { No. of Cells/ } \\
\text { Ilemisphere }\end{array}$ & $\begin{array}{c}\text { Approximate Diameter } \\
\text { of Somata }\end{array}$ & $\begin{array}{c}\text { Axon } \\
\text { Tract }\end{array}$ \\
\hline & & & $\mu$ & \\
Ia & Pars intercerebralis & 4 & 30 & I \\
Ib & Pars intercerebralis & $4-5$ & 15 & I \\
IIa & Pars lateralis & 2 & $20-25$ & II \\
IIb & Pars lateralis & $5-6$ & 20 & II \\
\hline
\end{tabular}
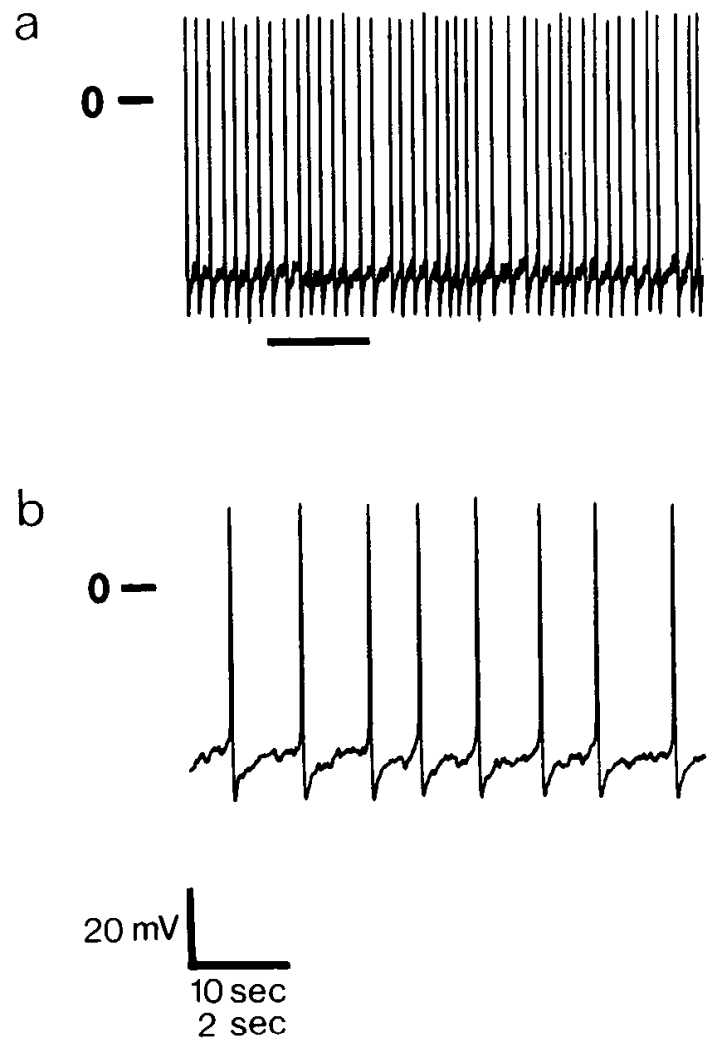

Figure 2. Spontaneous activity recorded intracellularly from a group Ia NSC from a pupa. a, Compressed record showing regular pattern of impulses. $b$, Expanded record (indicated by the bar in $a$ ) showing postsynaptic potentials. 

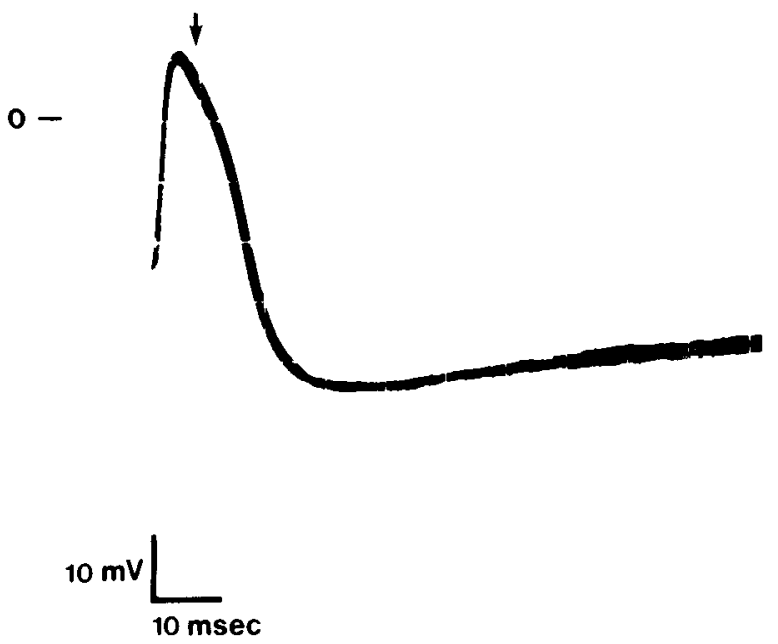

Figure 3. Ten superimposed spontaneous action potentials recorded from a group II cell. The arrow denotes inflection in downward slope.

impulses were greater than $50 \mathrm{mV}$ in amplitude, were long in duration (10 to $20 \mathrm{msec}$ at $50 \%$ height), and showed long hyperpolarizing afterpotentials. In addition, they had a characteristic inflection on the downward slope. Postsynaptic potentials were also apparent.

Dye injection. Injected horseradish peroxidase moved rapidly to the axon terminals, whereas staining of dendrites required greater amounts of enzyme and longer incubations. This observation may reflect active protein transport along the axons. Conversely, Lucifer Yellow spread rapidly to the dendrites but slowly to the axon terminals. Thus, the two materials were complementary in their cell marking characteristics. The observations reported here are based on complete fills of at least 20 cells in each of the groups.

Pressure injection of cobalt followed by silver intensification of the sulfide precipitate in whole mount (Strausfeld and Miller, 1980) resulted in NSC profiles that did not differ from those with HRP or Lucifer Yellow. Although the silver provided a denser image, the major difficulties that proscribed the further use of cobalt in desheathed pupal brains were the high background and the resultant brittleness of the tissue.

NSC architecture. All of the cells are monopolar with one or more neurites branching from the axon in the vicinity of the cell body. The axons project to the retrocerebral complex via the nervi corporis cardiaci I and II (NCC I + II) as shown in Figure $1 B$.

The cell bodies of the medial group Ia NSCs, as illustrated in Figure $1 A$, are usually aligned along the midline of the brain. Figures $4 A$ and 7 show that the dendrites of each cell spread profusely in both hemispheres stemming from about five major neurites that extend laterally from the midline along dorsal or ventral aspects of the brain. The dendritic field in each hemisphere seems to describe part of a cylindrical surface perpendicular to a frontal plane in the brain. Axons of these cells follow tract I by decussating, continuing along the ventral surface, and projecting to the surface of the contralateral CA where, as demonstrated by Figures $5 A$ and 7 , their terminals ramify and show varicosities.
By contrast to group Ia cells, the smaller group Ib somata are variable in number and relative position within the cluster. Their dendritic fields, depicted in Figures $4 B$ and 7 , are much less extensive than those of group Ia cells and are generally limited to the ipsilateral hemisphere. An exception is one cell type in which a major neurite and its dendritic arborization extended ventrally toward the tritocerebrum in one (HRP; $n=3$ ) or both (Lucifer Yellow; $n=1$ ) hemispheres. Axons of group Ib cells follow the same pathway as those of group Ia except that they terminate in the $\mathrm{CC}$, as shown in Figures $5 B$ and 7 .

A pair of somata, as demonstrated by Figure $1 A$, are consistently located most lateral and anterior in each hemisphere. Figures $4 C$ and 7 show that these group IIa cells are the only NSCs of the pars lateralis whose axons decussate in the brain. Their dendritic fields each describe an arc from below the soma to the pars intercerebralis and extending ventrally beyond the point of decussation of the axon; the dendrites are confined to the ipsilateral hemisphere. By contrast to cells of all the other groups whose dendrites stem from major neurites, about half of the dendrites of group IIa cells stem from the axon. The axons of these cells extend laterally along the dorsal aspect of the contralateral hemisphere; they then follow the tract II in this hemisphere and ramify in the CA, as shown in Figure 7.

Individual somata of group IIb lateral NSCs do not appear to be positioned in a consistent topographical pattern within the cluster. As shown in Figures $4 D$ and 7 , staining revealed one or more neurites in the ipsilateral hemisphere, some of which extend to the midline of the brain. In a few specimens, such as the one in Figure $4 D$, one of these neurites crossed the midline. The axons project ventrally along tract II and exit from the hemisphere ipsilateral to the soma. Figure 7 indicates that terminals of these cells ramify in either the $\mathrm{CC}$ or the CA but not in both. As illustrated in Figure 6, projections to the $\mathrm{CC}$ of some of these cells include extensions directed anteriorly or posteriorly along nerves which may innervate labial or stomodeal muscles or other tissues (Nijhout, 1975).

Cells tested in physiological experiments. The experiments described here required chronic recordings from the same cell over long periods of time; often, reimpalement of the cell was necessary. Because of their large size (about $30 \mu$ ), the group Ia somata were the most accessible to intracellular electrophysiology; therefore, experiments were focused on cells of this class. The data presented for each experiment are representative of group Ia cells in at least five replicates. The findings reported here were confirmed for two to five representatives of each of the other three groups of NSCs, by intermittent reimpalement at different times during the course of each experiment.

Effects of TTX. TTX is a blocker of most voltagesensitive sodium channels. Figure 8 shows that $10^{-5} \mathrm{M}$ TTX in the bathing medium blocked postsynaptic potentials and spontaneous activity after $50 \mathrm{~min}$. Yet, full amplitude action potentials could still be evoked by current injection. Medium with $5 \times 10^{-5}$ M TTX gave the same result. Bath changes alone (controls) had no 

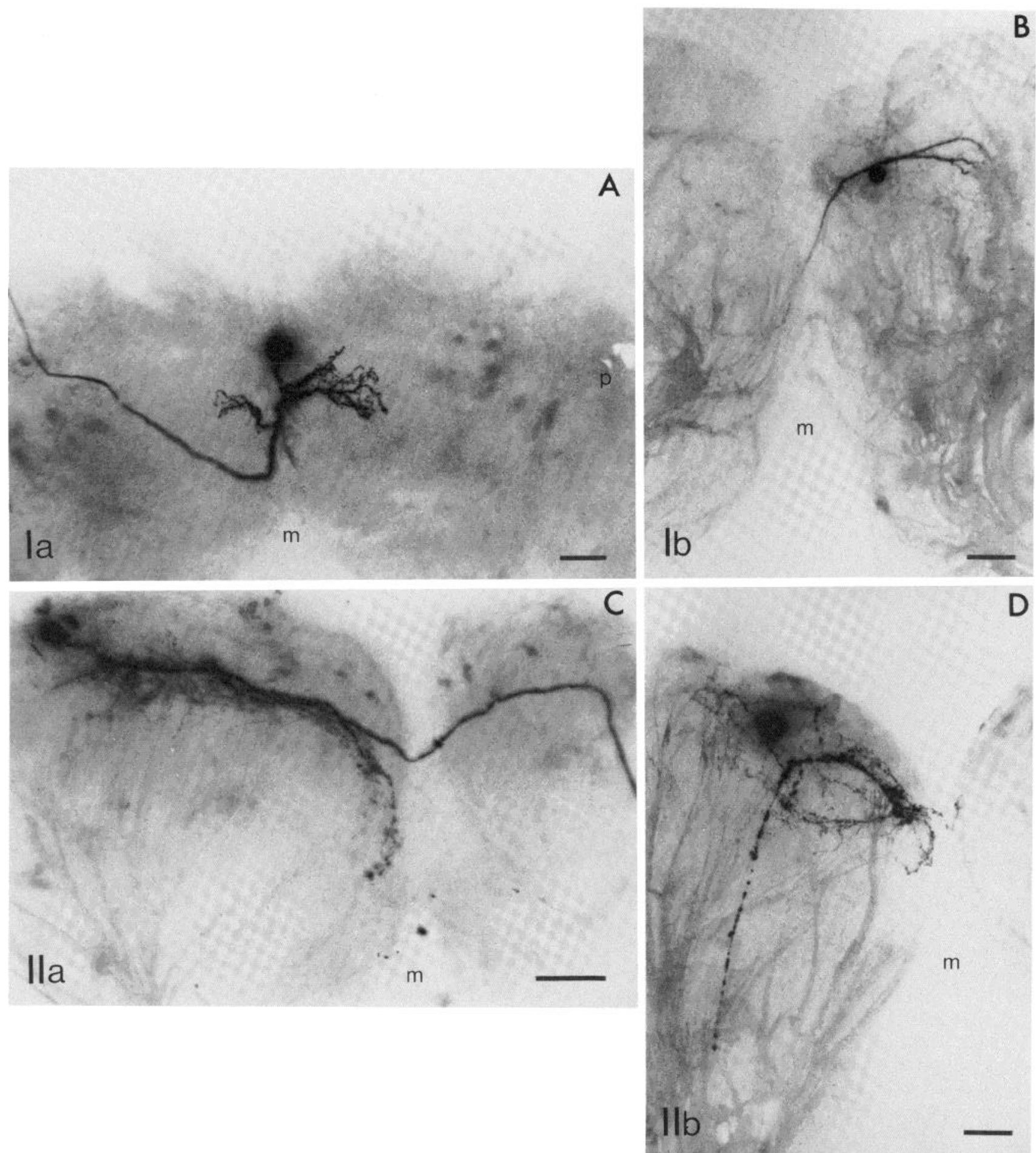

Figure 4. Dendritic architecture of representatives from the four groups of NSCs as revealed by Lucifer Yellow injection; negative images. $A$, Group Ia cell showing dendritic fields in both hemispheres and decussation of axon. This specimen was fixed, dehydrated, and cleared as described for HRP-injected tissues and mounted in the clearing agent. All other specimens were treated as described under "Materials and Methods." Left hemisphere is on the right, posterior is into the page. All other photographs are frontal views with the left hemisphere on the left and the dorsum upward. $B$, Group Ib cell showing major neurite in ipsilateral hemisphere and decussation of the axon. $C$, Group IIa cell illustrating dendritic field arching over left protocerebrum, decussation of axon, and joining of axon with tract II. $D$, Group IIb cell showing major neurites extending to and crossing midline; its axon does not decussate. $m$, midline of brain; $p$, pigment granules in optic lobe. Bar $=100 \mu$.

effect. Injection of the stock solution of TTX into larvae caused paralysis as expected (Williams, 1968).

Ion substitutions. As with TTX, addition of cobalt or removal of sodium or calcium required an hour or more to have effects. Naturally, this made chronic recording and tissue maintenance difficult. To eliminate some of the blood-brain barrier which might be responsible for the block to ion exchange, the tissue was subjected to light protease digestion. Protease (type XIV, Sigma) was added to the medium bathing the desheathed brain 

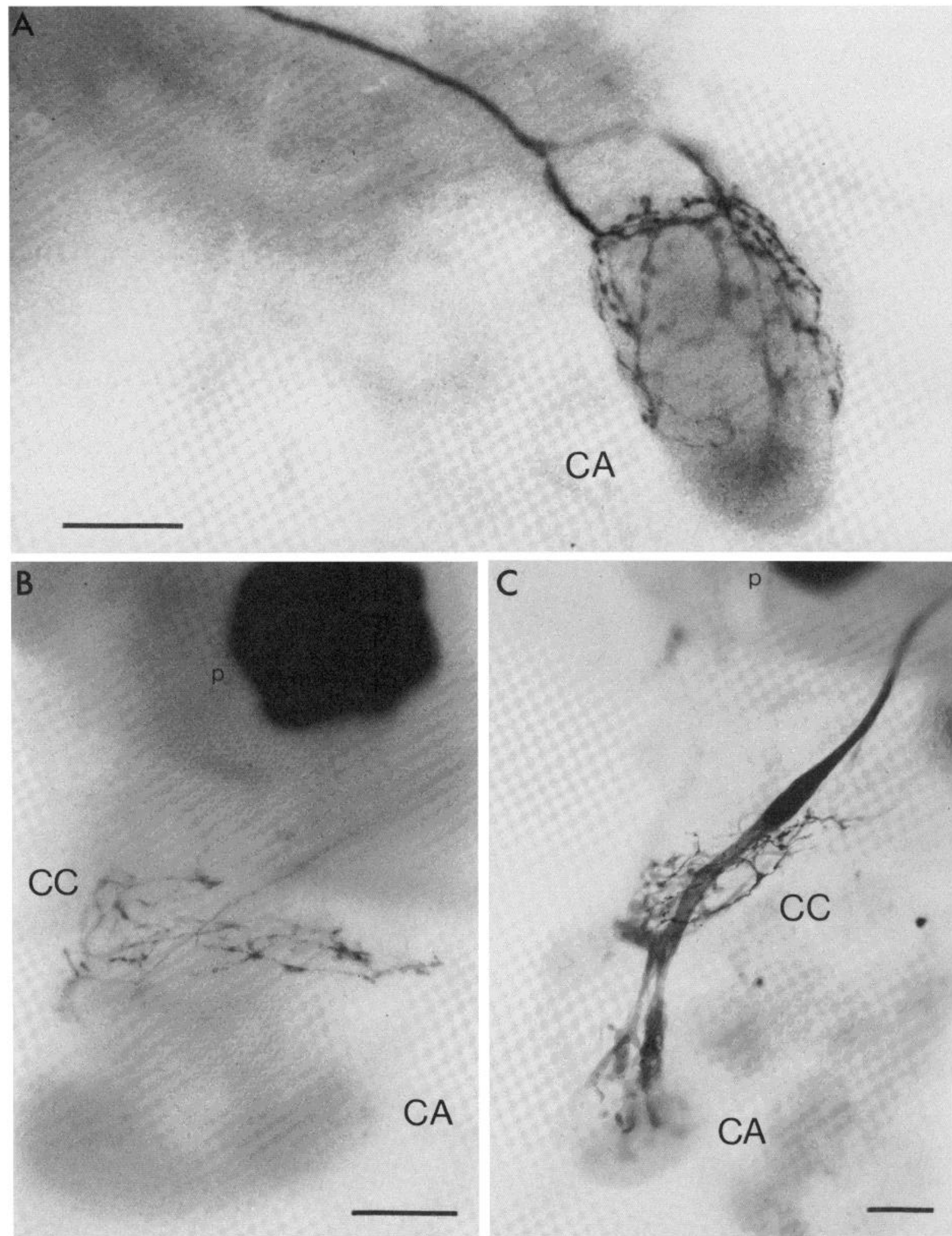

Figure 5. Details of terminal projections of cerebral NSCs in the neurohemal organs. A, Group Ia NSC injected with Lucifer Yellow; detail of terminal ramifications and varicosities on the surface of the CA. B, Group Ib NSC injected with HRP; detail of terminal ramifications and varicosities in the CC; terminals do not invade the CA. C, Multiple fill of NSC terminals resulting from injection of HRP into pars intercerebralis of one hemisphere; detail of terminal ramifications in both neurohemal organs. $p$, pigment granules in optic lobe. $B a r=100 \mu$. 


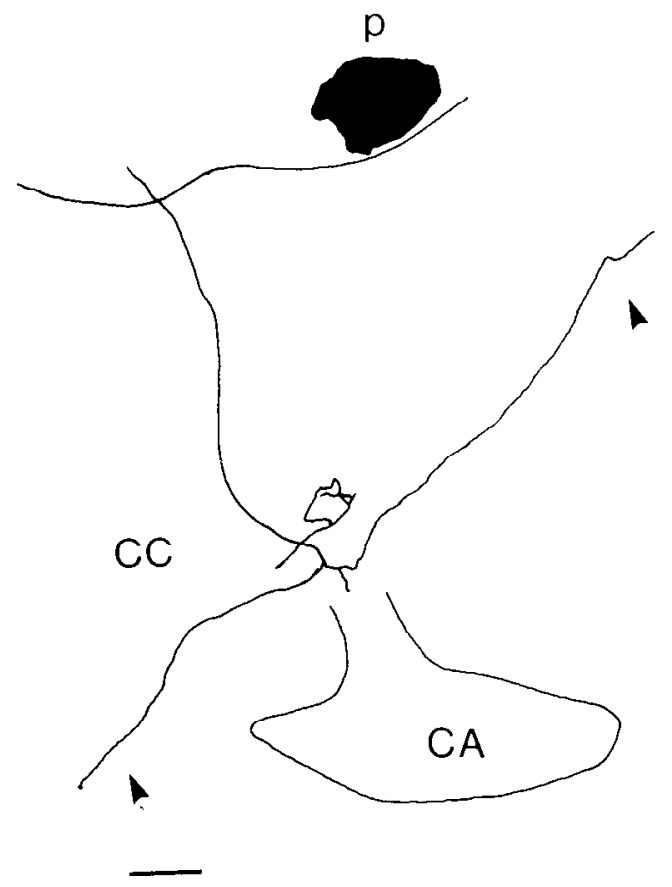

Figure 6. Camera Lucida drawing of the axon projections via the CC of an HRP-injected group IIb NSC, showing extended anterior and posterior projections (arrowheads) toward the brain and along the foregut. Anterior is upward. $p$, pigment granules in optic lobe. $B a r=100 \mu$.

at a concentration of about $0.25 \mathrm{mg} / \mathrm{ml}$. After a minute of exposure the protease was washed out thoroughly. All further data presented are from brains so treated; however, as already indicated, the experiments were confirmed for brains not treated with protease.

Effects of sodium-free medium. As illustrated in Figure 9 , replacement of the bathing medium with one lacking sodium blocked postsynaptic potentials and spontaneous activity but had no discernible effect on NSC excitability. Thus, full amplitude action potentials were evoked by the injection of depolarizing current. Twenty minutes after reintroduction of sodium, the cell returned to its previous condition of showing postsynaptic potentials and spontaneous impulses.

Effects of cobalt. Figure 10 shows that $10 \mathrm{~mm}$ cobalt blocked most postsynaptic potentials after $10 \mathrm{~min}$, and impulses evoked by current injection were much reduced in amplitude. Action potentials progressively decreased in amplitude until they could not be evoked even with greater amounts of current after an additional $10 \mathrm{~min}$. Postsynaptic potentials and full amplitude action potentials returned $20 \mathrm{~min}$ after washout of the cobalt. In experiments on brains not subjected to protease, $10 \mathrm{mM}$ cobalt gave a similar result, but $5 \mathrm{mM}$ cobalt had no effect even after an hour of exposure.

Effects of calcium-free medium. Electrical activity of the NSCs was normal in medium without added calcium. This was probably due to trace amounts of extracellular calcium since addition of $10^{-3}$ M EGTA, a calcium chelator, irreversibly blocked all electrical activity. Furthermore, in brains treated with protease, some diminution in impulse amplitude was occasionally observed after 30 min in calcium-free medium.

\section{Discussion}

The architecture of individual neurosecretory cells in an insect brain was revealed by the intracellular injection of Lucifer Yellow and horseradish peroxidase. Moreover, the ionic basis of the action potential in these cerebral neurons was determined by intracellular impalement of identified somata.

Individual NSCs were examined from four groups visible in the living pupal brain of $M$. sexta. The configuration and temporal characteristics of the action potentials observed in these NSCs conform to observations of other invertebrate and vertebrate NSCs (see Maddrell and Nordmann, 1979 for review). Although all the neurons are monopolar, they are distinguishable by the size and topographical position of their somata, their dendritic fields, their axon pathways, and the sites of axon terminal ramification. The architecture of the cells is consistent among members of a group but is unlike that of cells in every other group.

The NSCs have group-specific patterns of dendritic arborization. Cells in groups Ia and IIa show extensive dendritic arborization, whereas those in groups $\mathrm{Ib}$ and IIb have smaller somata and fewer dendrites. Two subclasses of group Ib cells were distinguished on the basis of dendritic architecture-one with a dorsal field and the other with a ventral field. The description of dendritic fields of individual NSCs provided here is compatible with the general picture obtained by retrograde cobalt filling of the NCC I and II in larval brain (Buys and Gibbs, 1981).

The extensive arborization of many of the NSCs and the apparent overlap of dendritic fields within and be tween clusters suggests considerable intercommunication among NSCs or between groups of NSCs and other cells. This is expected at least for those of the cells which produce PTTH since mechanosensory and photic inputs have been implicated in the control of PTTH release in Manduca (Truman, 1972; Nijhout and Williams, 1974; Truman and Riddiford, 1974). Thus, the prothoracicotropes or their presynaptic driver cells must integrate many inputs. Organization of these activities may be a function of the superior and inferior protocerebral neuropils (Strausfeld, 1976) since the dendritic fields of the cerebral NSCs seem to circumscribe this brain region.

All the NSC axons exit from the brain via one of the bilaterally paired and fused NCC I and II; however their pathways within the brain differ. Only the axons of group IIb fail to decussate, corroborating the results of retrograde cobalt filling (Nijhout, 1975). The pattern of projection within the axon tracts is consistent with that found for other species in that the axons of cells of the pars intercerebralis decussate and follow tract I while those of cells of the pars lateralis do not decussate and instead follow tract II (Mason, 1973; Pipa, 1978; Koontz and Edwards, 1980). However, in Manduca, the group IIa lateral cells are exceptional in that they decussate prior to joining tract II in the opposite hemisphere. The developmental origin and the function of this anomalous pathway remain to be determined.

The cerebral NSCs were further distinguished by their terminal projections. Cells of groups Ia and IIa project 


\section{Group Structure}

la

Ib

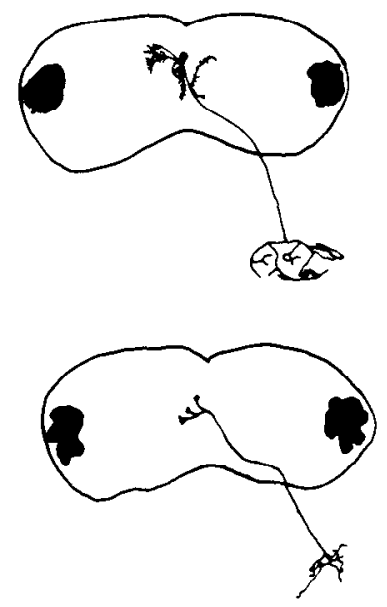

$11 a$

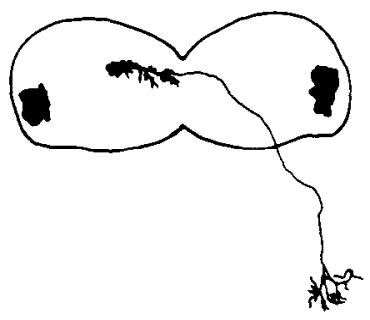

$11 b$

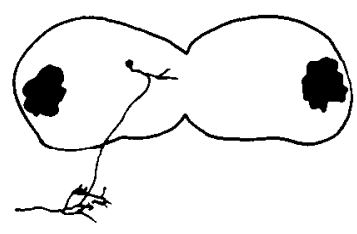

Projection

CA

C C

CA

Figure 7. Architecture of the cerebral NSCs of pupal M. sexta; summary of results. The camera lucida drawings are of HRPinjected cells whose somata lie in the left hemisphere. $B a r=100 \mu$.

a

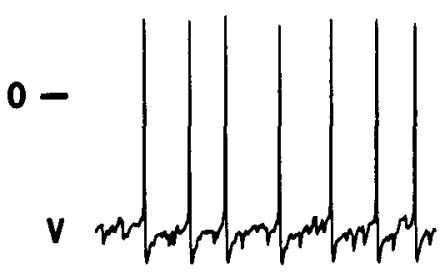

I

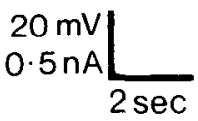

Figure 8. Effects of TTX on a group Ia cell. $a$, Spontaneous activity recorded in normal medium. $b$, Impulses evoked by current injection after 50 -min exposure to $10^{-5} \mathrm{M}$ TTX. Note disappearance of postsynaptic potentials. b
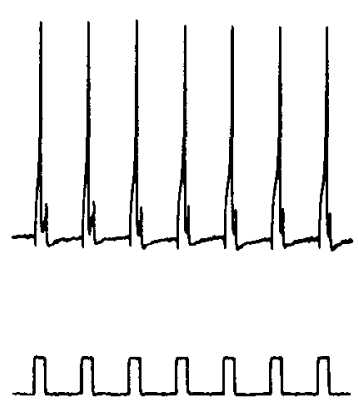

to the CA, whereas those of group Ib project to the CC. Within group IIb, some cells ramify in the CC and others terminate in the $\mathrm{CA}$, demonstrating at least two subclasses within this group. In no case did any one cerebral NSC show terminal ramifications in both organs. Terminal varicosities were apparent throughout the $\mathrm{CC}$ and on the surface of the CA, suggesting neurohemal storage or release areas. These observations provide direct anatomical confirmation of the physiological evidence that the $\mathrm{CC}$ and $\mathrm{CA}$ are neurohemal organs for insect cerebral neurosecretory cells (Carrow et al., 1981). In addition, some terminal projections indicate a possible neuromodulatory rather than neurohemal function for some of the NSCs. That is, the extended anterior and posterior projections of some group IIb cells along nerves that exit from the $\mathrm{CC}$ as well as the terminal ramifications of other cells within the glandular portion of the CA suggest direct delivery of neurosecretions to target tissues.

Thus, at least six different morphological classes were distinguished among the four groups of NSCs. Further subdivisions within each group might be made on the 
basis of other criteria, such as staining properties (Herman and Gilbert, 1965), ultrastructure (Borg and Bell, 1977), or unique dendritic and terminal patterns. It is not possible to discern whether the morphological classes identified here are also functionally distinct. However, the number of classes is in proportion to the estimated minimum number of brain neurosecretions (Rowell, 1976), which suggests a specific neuroendocrine function for each class.

Among the cerebral NSCs examined in this study are those which produce PTTH. Agui and colleagues (1979)
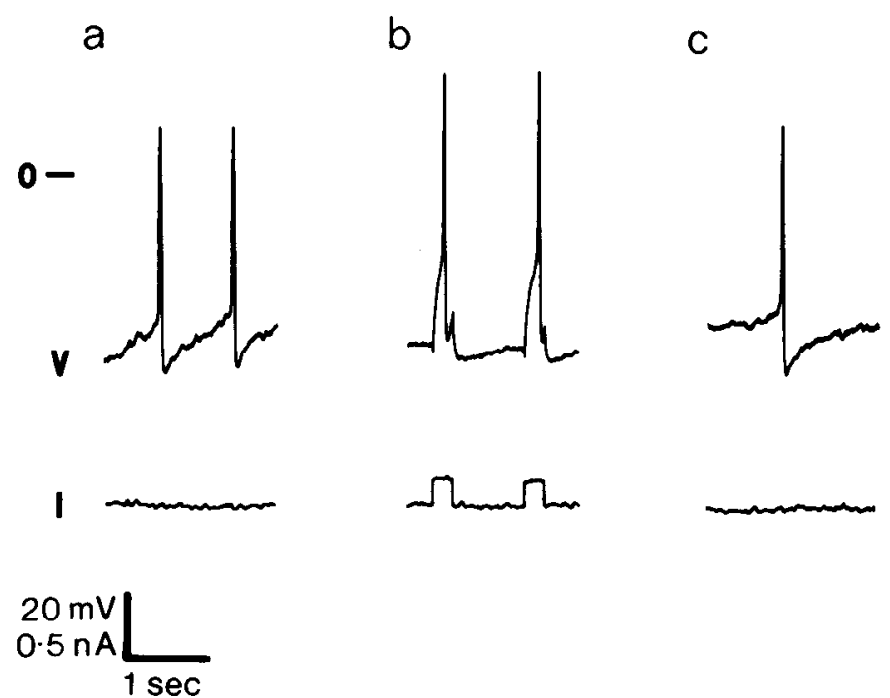

Figure 9. Effects of sodium-free medium on a group Ia NSC. $a$, Spontaneous activity recorded in normal medium. $b$, Impulses evoked by current injection $25 \mathrm{~min}$ after removal of sodium and substitution with Tris (the larger overshoot is due to a bridge imbalance). $c$, Recovery of spontaneous activity $20 \mathrm{~min}$ after reintroduction of sodium. Note reduction of postsynaptic activity in $b$. localized most of the PTTH activity stored in the brain to a single soma in the pars lateralis in each hemisphere. Although no retrograde cobalt filling was performed to distinguish between the two groups in this region, the PTTH-containing cell was consistently one of a pair of cells located most laterally in the brain (N. Agui, personal communication). Since the observations reported here indicate that these are group IIa cells, it appears that one of them is the primary PTTH cell. The fact, established here, that group IIa cells project to the CA-the primary neurohemal organ for PTTH (Gibbs and Riddiford, 1977; Agui et al., 1980; Carrow et al., 1981) lends further support to the hypothesis that one of these cells is the primary prothoracicotrope. We observed that group IIa cells are unique among the NSCs in that many of their dendrites stem from the axon rather than from major neurites. The roles of axonal dendrites or the unique axonal pathway in the function of these putative PTTH cells remain to be determined.

Evidence presented here shows that the action potentials in these NSCs are insensitive to high concentrations of 'IXX, independent of external sodium, and blocked by cobalt. These data indicate that impulses in the somata of these neurons are generated predominantly or entirely by an inward calcium current (Hagiwara and Byerly, 1981).

Postsynaptic potentials and spontaneous action potentials were blocked in sodium-free medium, as well as by TTX or cobalt. Thus, failure to block excitability under the first two conditions was not likely due to inaccessibility of the cells to the bathing medium. Furthermore, these results show that synaptic inputs are dependent upon both sodium and calcium and that spontaneous impulse activity in the soma is, in turn, dependent upon synaptic input.

Observations made here provide evidence for an intact blood-brain barrier in these desheathed ganglia. An hour
C
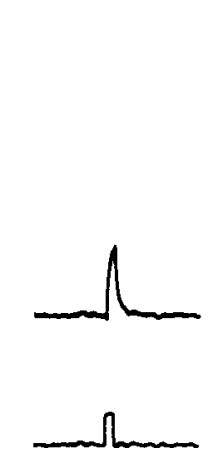

d

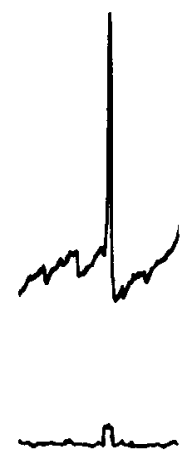

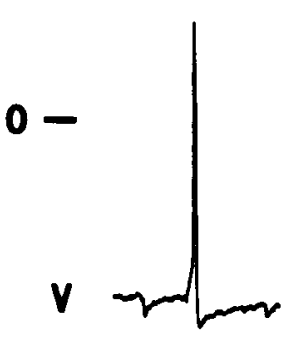

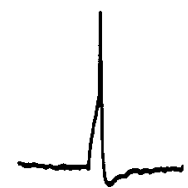

I
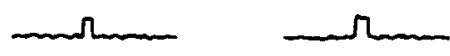

Figure 10. Effects of cobalt on a group Ia NSC. $a$, Action potential evoked in normal medium by current injection. $b$, Impulse of reduced amplitude evoked by current injection $10 \mathrm{~min}$ after addition of $10 \mathrm{~mm}$ cobalt. $c$, Subsequent failure to evoke an action potential with increased current injection. $d$, Recovery of evoked activity $30 \mathrm{~min}$ after washout of cobalt. 
or more was required before the effects of TTX or cobalt were evident; moreover, calcium-free media had no effect. Evidently, these substances do not diffuse readily through the remaining perineurium (Treherne, 1974). Additional indications of the integrity of the perineurial barrier were that (i) HRP applied to the surface of the brain did not penetrate the underlying tissue, and (ii) light protease treatment of the desheathed brain promoted ion exchange.

EGTA immediately and irreversibly blocked electrical activity in the NSCs even in the presence of calcium. This observation is consistent with the evidence for a calcium inward current, but the irreversibility suggests that calcium is necessary for the integrity of the cells. Perhaps the ion is required for the function of essential extracellular calcium-binding proteins (Levine and Williams, 1982).

The detection of action potentials generated primarily by calcium inward currents in the NSC somata of Manduca as well as in two other species (Orchard, 1976; Miyazaki, 1980) suggests that this may be a generalized phenomenon in insect NSCs. Whether calcium has additional functions in the soma remains to be determined. The role of calcium in excitation-secretion coupling in neuron terminals is well established (Douglas, 1978) and has been confirmed for insect NSCs (Maddrell and Gee, 1974; Carrow et al., 1981). Some workers have speculated that the inward calcium current of developmentally immature neurons may be related to the great degree of synthetic activity which must accompany their growth and differentiation (Spitzer, 1979). Similarly, in mature NSCs, calcium influx may regulate the synthesis or transport of the substantial amounts of neurohormone involved.

The resolution of the problems raised here will ultimately require concomitant measurement of membrane currents and neurohormone synthesis, transport, and release. Few neuroendocrine systerns are sufficiently well defined to be accessible to physiological, anatomical, and biochemical analysis. The framework of anatomical and physiological parameters of the cerebral NSCs provided here should facilitate analysis of single, identified cells and thus contribute to our understanding of the function of endocrine neurons.

\section{References}

Agui, N., N. A. Granger, L. I. Gilbert, and W. E. Bollenbacher (1979) Cellular localization of the insect prothoracicotropic hormone: In vitro assay of a single neurosecretory cell. Proc. Natl. Acad. Sci. U. S. A. 76: 5694-5698.

Agui, N., W. E. Bollenbacher, N. A. Granger, and L. I. Gilbert (1980) Corpus allatum is release site for insect prothoracicotropic hormone. Nature 285: 669-670.

Bell, R. A., and F. G. Joachim (1976) Techniques for rearing laboratory colonies of tobacco hornworms and pink bollworms. Ann. Entomol. Soc. Am. 69: 365-373.

Borg, T. K., and R. A. Bell (1977) Ultrastructure of the neurosecretory cells in the brain of diapausing pupae of the tobacco hornworm, Manduca sexta (L). Tissue Cell 9: 567574.

Buys, C. M., and D. Gibbs (1981) The anatomy of neurons projecting to the corpus cardiacum from the larval brain of the tobacco hornworm, Manduca sexta (L.). Cell Tissue Res. 215: 505-513.

Carrow, G. M. (1983) Physiology and architecture of insect cerebral neurosecretory cells. Ph.D. thesis, Harvard University, Cambridge, MA.

Carrow, G. M., R. L. Calabrese, and C. M. Williams (1981) Spontaneous and evoked release of prothoracicotropin from multiple neurohemal organs of the tobacco hornworm. Proc. Natl. Acad. Sci. U. S. A. 78: 58665870.

Carrow, G. M., R. L. Calabrese, and C. M. Williams (1982) Protocerebral neuroendocrine system of the tobacco hornworm: Morphology and physiology of identifiable neurosecretory cells. Soc. Neurosci. Abstr. 8: 532 .

Douglas, W. W. (1978) Stimulus-secretion coupling: Variations on the theme of calcium-activated exocytosis involving cellular and extracellular sources of calcium. Ciba Found. Symp. 54: $61-90$.

Geduldig, D., and D. Junge (1968) Sodium and calcium components of action potentials in the Aplysia giant neurone. J. Physiol. (Lond.) 199: 347-365.

Gibbs, D., and L. M. Riddiford (1977) Prothoracicotropic hormone in Manduca sexta: Localization by a larval assay. J. Exp. Biol. 66: 255-266.

Hagiwara, S., and I. Ryerly (1981) Calcium channel. Annu. Rev. Neurosci. 4: 69-125.

Herman, W. S., and L. I. Gilbert (1965) Multiplicity of cell types and groups in the brain of the Saturniid moth Hyalophora cecropia. Nature 205: 926-927.

Iwasaki, S., and Y. Satow (1971) Sodium- and calcium-dependent spike potentials in the secretory neuron soma of the Xorgan of the crayfish. J. Gen. Physiol. 57: 216-238.

Koontz, M., and J. S. Edwards (1980) The projection of neuroendocrine fibers (NCC I and II) in the brains of three orthopteroid insects. J. Morphol. 165: 285-299.

Levine, B. A., and R. J. P. Williams (1982) Calcium binding to proteins and other large biological anion centers. In Calcium and Cell Function, W. Y. Cheung, ed., Vol. II, Academic Press, Inc., New York.

Maddrell, S. H. P., and J. D. Gee (1974) Potassium-induced release of the diuretic hormone of Rhodnius prolixus and Glossina austeni: Ca dependence, time course and localization of neurohemal areas. J. Exp. Biol. 61: 155-171.

Maddrell, S. H. P., and J. J. Nordmann (1979) Neurosecretion, John Wiley \& Sons, New York.

Mason, C. A. (1973) New features of the brain-retrocerebral neuroendocrine complex of the locust Schistocerca vaga (Scudder). Z. Zellforsch. 141: 1932.

Miller, T. A. (1979) Insect Neurophysiological Techniques, Springer-Verlag, New York.

Miyazaki, S. (1980) The ionic mechanism of action potentials in neurosecretory cells and non-neurosecretory cells of the silkworm. J. Comp. Physiol. 140: 43-52.

Muller, K. J., and U. J. McMahan (1976) The shapes of sensory and motor neurones and the distribution of their synapses in ganglia of the leech: A study using intracellular injection of horseradish peroxidase. Proc. R. Soc. Lond. Biol. 194: 481499.

Nijhout, H. F. (1975) Axonal pathways in the brain-retrocerebral complex of Manduca sexta (L.) (Lepidoptera: Sphingidae). Int. J. Insect Morphol. Embryol. 4: 529-538.

Nijhout, H. F., and C. M. Williams (1974) Control of moulting and metamorphosis in the tobacco hornworm Manduca sexta (L.).: Growth of the last-instar larva and the decision to pupate. J. Exp. Biol. 61: 481-491.

Orchard, I. (1976) Calcium dependent action potentials in a peripheral neurosecretory cell of the stick insect. J. Comp. Physiol. 112: 95-102.

Orchard, I., and M. P. Osborne (1977) The effects of cations upon the action potentials recorded from neurohaemal tissue of the stick insect. J. Comp. Physiol. 118: 1-12.

Pipa, R. L. (1978) Locations and central projections of neurons associated with the retrocerebral neuroendocrine complex of 
the cockroach Periplaneta americana (L.). Cell Tissue Res. 193: 443-455.

Raabe, M. (1982) Insect Neurohormones, Plenum Press, New York.

Rowell, H. F. (1976) The cells of the insect neurosecretory system: Constancy, variability, and the concept of the unique identifiable neuron. Adv. Insect Physiol. 12: 63-121.

Spitzer, N. C. (1979) Ion channels in development. Annu. Rev. Neurosci. 2: 363-397.

Standen, N. B. (1975) Calcium and sodium ions as charge carriers in the action potentials of an identified snail neurone. J. Physiol. (Lond.) 249: 241-252.

Stewart, W. W. (1978) Functional connections between cells as revealed by dye-coupling with a highly fluorescent naphthalimide tracer. Cell 14: 741-759.

Strausfeld, N. J. (1976) Atlas of an Insect Brain, SpringerVerlag, Berlin.

Strausfeld, N. J., and T. A. Miller (1980) Neuroanatomical Techniques. Insect Nervous System, Springer-Verlag, New York.
Taghert, P. H., and J. W. Truman (1982) Identification of the bursicon-containing neurones in abdominal ganglia of the tobacco hornworm, Manduca sexta. J. Exp. Biol. 98: 385-401.

Treherne, J. E. (1974) The environment and function of insect nerve cells. In Insect Neurobiology, J. E. Treherne, ed., American Elsevier, New York.

Truman, J. W. (1972) Physiology of insect rhythms. I. Circadian organization of the endocrine events underlying the moulting cycle of larval tobacco hornworms. J. Exp. Biol. 57: $805-820$.

Truman, J. W., and L. M. Riddiford (1974) Physiology of insect rhythms. III. The temporal organization of the endocrine events underlying pupation of the tobacco hornworm. J. Exp. Biol. 60: 371-382.

Williams, C. M. (1968) Tetrodotoxin: A nonlethal paralytic agent for insects. Science 160: 444.

Zaretsky, M. D., and W. J. Loher (1982) Structure of individual neurosecretory cells of the brain in crickets. Soc. Neurosci. Abstr. 8: 532. 